Review

\title{
Surface-Engineered Fire Protective Coatings for Fabrics through Sol-Gel and Layer-by-Layer Methods: An Overview
}

\author{
Giulio Malucelli \\ Department of Applied Science and Technology, Politecnico di Torino, Viale Teresa Michel 5, \\ Alessandria 15121, Italy; giulio.malucelli@polito.it; Tel.: +39-0131-229369; Fax: +39-0131-229399 \\ Academic Editor: Alessandro Lavacchi \\ Received: 12 June 2016; Accepted: 27 July 2016; Published: 29 July 2016
}

\begin{abstract}
Fabric flammability is a surface-confined phenomenon: in fact, the fabric surface represents the most critical region, through which the mass and heat transfers, responsible for fueling the flame, are controlled and exchanged with the surroundings. More specifically, the heat the fabric surface is exposed to is transferred to the bulk, from which volatile products of thermal degradation diffuse toward the surface and the gas phase, hence feeding the flame. As a consequence, the chemical and physical characteristics of the fabric surface considerably affect the ignition and combustion processes, as the surface influences the flux of combustible volatile products toward the gas phase. In this context, it is possible to significantly modify (and improve) the fire performance of textile materials by "simply" tailoring their surface: currently, one of the most effective approaches exploits the deposition of tailored coatings able to slow down the heat and mass transfer phenomena occurring during the fire stages. This paper reviews the current state of the art related to the design of inorganic, hybrid, or organic flame-retardant coatings suitable for the fire protection of different fabric substrates (particularly referring to cotton, polyester, and their blends). More specifically, the use of sol-gel and layer-by-layer (LbL) methods is thoroughly discussed; then, some recent examples of flame retardant coatings are presented, showing their potential advances and their current limitations.
\end{abstract}

Keywords: flame retardants; fire protective coatings; surface engineering; sol-gel treatments; layer-by-layer architectures; thermal stability; fire tests

\section{Introduction}

Plastics and textiles play an important role in everyday life: they consist mainly of organic polymers, which are flammable and potentially dangerous species. As recently reported by the International Association of Fire and Rescue Services, from 1993 to 2013 fire statistics from 27-57 countries, collectively representing 0.9-3.8 billion inhabitants of the Earth, documented 3.1-4.5 million fires and 24,000-62,000 fire deaths. In particular, statistics indicate that in 32 countries, representing $15 \%$ of the world's population, 49 million calls ( 45.3 calls per 1000 inhabitants), 2.5 million fires (5.1\% of all calls, 2.4 fires per 1000 inhabitants), 21.7 thousand fire deaths (2.0 fire deaths per 100,000 inhabitants), and 65.8 thousand fire injuries (6.1 fire injuries per 100,000 inhabitants) occurred [1]. More specifically, most of the deaths derive from inhalation of smoke and toxic combustion gases, carbon monoxide being the most common cause; the injuries result from exposure to the heat from fires. Specifically referring to textiles, the annual UK fire statistics, being some of the most comprehensive available and attempting to provide information representative of a European country with a population of about 60 million, show that most fire incidents occur in the home, involving upholstered furniture, bedding, and nightwear [2]. 
In this context, the ease of flammability of plastics and textiles has been faced by designing and developing several flame retardants (FRs), i.e., additives that aim to decrease the risk of fire by inhibiting the possibility of the material igniting or slowing down the rate of flame spread when needed.

Generally speaking, flaming combustion is a gas-phase oxidative process: for this reason, it demands oxygen (or air) from the atmosphere. Therefore, before undertaking flaming combustion, the polymer has to degrade: the degradation promotes the formation of combustible volatile species that can mix together with atmospheric oxygen and fuel a flame. Because of the high exothermic character of the flame, when the heat transferred to the material surface is enough, it may give rise to further degradation, hence promoting a self-sustaining combustion cycle (Figure 1).

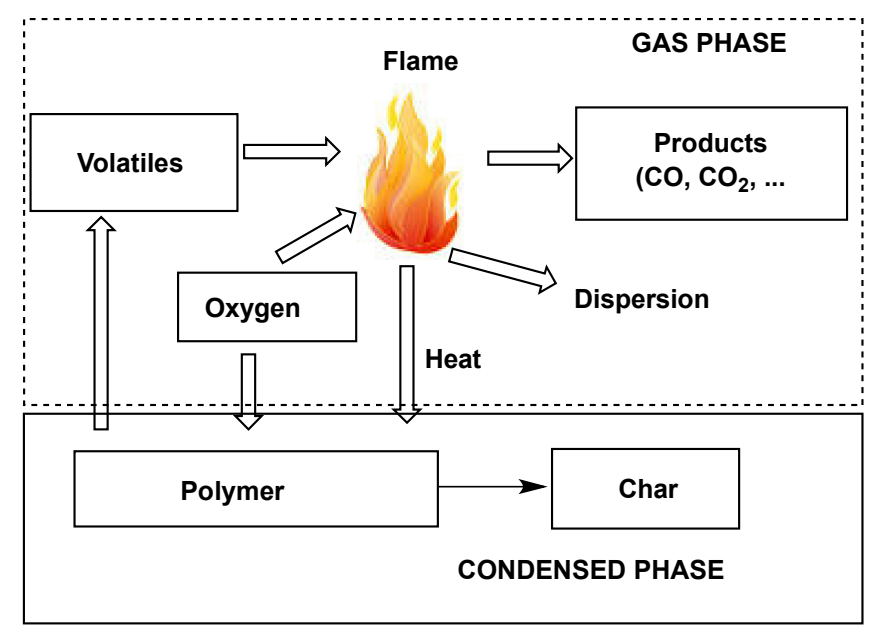

Figure 1. Scheme of the polymer combustion cycle.

Depending on the chemical composition and on their thermal and fire properties, textile fibers and fabrics need substances such as halogen, sulfur, phosphorus, nitrogen, boron, metals, etc. to attain flame retardancy [3,4]. These additives can be directly introduced into synthetic fibers during the spinning process (for example, grafting to the polymer backbone or copolymerization reactions), or can be deposited on the synthetic or natural fiber/fabric surface $[5,6]$. These surface treatments can be performed either using finishing or coating techniques: the former involve the impregnation of the fabric in a solution/stable suspension of the flame-retardant additive; the latter involve the application of a continuous or discontinuous layer/film on both the outer surface and back of the fabric.

FRs act to break the textile's self-sustaining combustion cycle, thus providing flame extinction or a reduction of the burning rate; in particular, as shown in Figure 2, they are able to:

- reduce the heat to below that needed to sustain combustion;

- modify the pyrolysis process to reduce the amount of flammable volatiles in favor of increasing the formation of a less flammable carbonaceous residue (char), which also acts as a barrier between the polymer and the flame (a);

- $\quad$ isolate the flame from the oxygen/air supply $(b)$;

- release chlorine or bromine atoms when the polymer is heated to near the ignition temperature; chlorinated and particularly brominated compounds are very efficient flame inhibitors $(c)$;

- decrease the heat flow back to the polymer to prevent further pyrolysis;

- arrange that a barrier, e.g., char or an intumescent coating, is formed when the polymer is exposed to fire conditions $(d)$. 


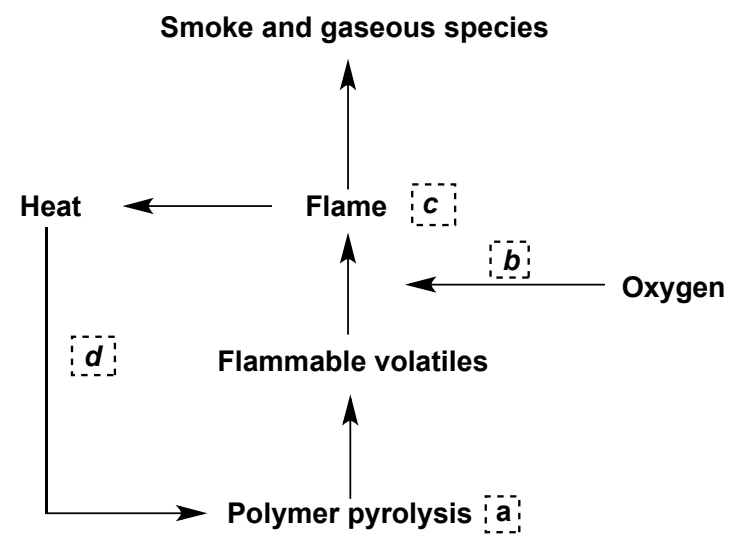

Figure 2. Potential modes of flame retardant action in a self-sustaining polymer combustion cycle (adapted from [6]).

Horrocks reviewed the types of FRs currently available on the market for fibers and fabrics [7], highlighting the distinctions between them through an historical re-development, based on the following periods:

- the "golden period" of flame retardant research (1950-1980), characterized by the development of the first patents for organophosphorus-based FRs for cotton together with the production of inherently flame retardant synthetic fibers based on aromatic-structured polymer chains;

- $\quad$ the 1980s-late 1990s period, showing very little novel research in this area;

- the 2000 onward period, during which several attempts were and are being made to develop and improve char-promoting FRs, eventually coupled with phosphorus-containing additives. During this period, the possible replacement of bromine derivatives was also taken into account. Furthermore, this was the period during which nanotechnology was proven to be exploitable for conferring flame retardancy to fabrics, through the creation of self-assembled nanolayer films made of nanoparticles. More specifically, top-down and bottom-up strategies have been successfully utilized: the former uses preformed nanoparticle suspensions, while the bottom-up approach involves the creation of single or aggregates/assemblies of different types of nanoparticles.

Specifically referring to surface-engineered coatings, different approaches have been investigated: generally speaking, they allow the deposition of films, even less than $100 \mathrm{~nm}$ of thickness, often exploiting environmentally friendly technologies. Many techniques can be used to achieve the atomistic/molecular deposition of the coatings, such as physical vapor deposition (PVD), chemical vapor deposition (CVD), electro plating or electroless plating, laser vaporization, plasma deposition, or plasma-based CVD [8]. More specifically, the sputtering technology was utilized to deposit very thin films on the nanocomposite fibers: PA6 nanofibers containing organo-modified Fe-montmorillonite were obtained and coated by silicon nanoparticles using the magnetron sputter technique [9]. The proposed surface treatment was found to be durable and to improve the burning behavior of the obtained nanocomposite fibers.

Plasma technologies have been widely applied to textiles, aiming either at modifying the structure of the surface or at depositing nanostructured coatings onto the surface. Different deposition conditions, such as low or atmospheric pressure, types of power, and the use of polymerizable or non-polymerizable gases, can be exploited. In particular, the main reasons that justify the use of atmospheric rather than low-pressure plasma for depositing nanostructured coatings on textile substrates are the excellent adhesion of these coatings to the textile substrate and the cost-effective continuous process operation [10]. Dineff et al. were the first to suggest that atmospheric plasma could improve the adhesion of non-halogenated flame-retardant coatings on textile substrates [11]. 
Furthermore, coatings from nanoparticle adsorption (which represents the easiest way of pursuing a surface modification using nanoparticles) performed after plasma pre-treatments were utilized for improving the flame retardancy of PET and cotton fabrics: the obtained deposited coatings also showed good levels of durability/washing fastness [12-15].

Among the surface engineering approaches, the sol-gel and layer-by-layer techniques have recently attracted the attention of several researchers, as documented by the high number of papers published in the last 10 years. Despite significant differences (in fact, unlike LbL, which is a top-down approach, the sol-gel method is an example of a bottom-up strategy), these two methods aim at protecting the fiber or fabric surface through the formation of a surface barrier (fully inorganic or hybrid organic-inorganic as far as sol-gel is considered; fully inorganic, hybrid organic-inorganic, or fully organic if related to $\mathrm{LbL}$ ) able to retard oxygen diffusion into the fabric and slow down pyrolysis.

Table 1 shows the main differences between the two strategies.

Table 1. Sol-gel vs. layer-by-layer: pros and cons.

\begin{tabular}{|c|c|c|}
\hline Feature & Sol-Gel & Layer-by-Layer \\
\hline Main approach & $\begin{array}{l}\text { chemistry-based process } \\
\text { - usually accompanied by the } \\
\text { formation of by-products }\end{array}$ & $\begin{array}{l}\text { - usually based on } \\
\text { physical interactions }\end{array}$ \\
\hline Process sustainability & $\begin{array}{l}\text { usually poor, due to the use of high } \\
\text { impact chemical precursors }\end{array}$ & $\begin{array}{l}\text { good, but strictly related to the } \\
\text { components of the layers }\end{array}$ \\
\hline $\begin{array}{c}\text { Durability } \\
\text { (washing fastness) }\end{array}$ & - $\quad$ usually good & - usually low \\
\hline $\begin{array}{l}\text { Compatibility with } \\
\text { existing textile finishing } \\
\text { processes }\end{array}$ & $\begin{array}{l}\text { good (due to the possibility of using } \\
\text { standard industrial } \\
\text { impregnation/exhaustion techniques) }\end{array}$ & $\begin{array}{l}\text { low (notwithstanding the } \\
\text { possibility of developing } \\
\text { continuous roll-to-roll plants) }\end{array}$ \\
\hline $\begin{array}{l}\text { Comfort of the treated } \\
\text { textiles (in terms of } \\
\text { stiffness and touch) }\end{array}$ & $\begin{array}{l}\text { quite low, depending on the use of } \\
\text { fully inorganic or hybrid precursors }\end{array}$ & $\begin{array}{l}\text { - usually good, regardless of the } \\
\text { types of components of the layers }\end{array}$ \\
\hline $\begin{array}{c}\text { Multifunctionality of } \\
\text { the treatment }\end{array}$ & - $\quad$ achievable & - $\quad$ achievable \\
\hline
\end{tabular}

Thanks to the availability of different precursors (i.e., (semi)metal alkoxides or polyelectrolytes/nanofillers, referring to sol-gel and to LbL, respectively), it is possible to accurately design the coating deposited on the textile, hence tuning the final envisaged properties to provide the substrate with. Conversely, as will be discussed in the next paragraphs, there are still several challenging issues to consider, mainly referring to the washing fastness of the selected treatments and to the scale-up of the processes for industrial exploitation.

This paper reviews the current state of the art related to the fire protection of different fabric substrates (mainly cotton, polyester, and their blends), achieved by exploiting sol-gel and LbL strategies: to this end, some recent examples of the effectiveness of engineered flame-retardant coatings are discussed, showing their potential innovations and their current limitations.

\section{Sol-Gel Derived Coatings on Fabrics}

The sol-gel technique has already shown its exceptional potential concerning the design of new materials having a high degree of homogeneity at the molecular scale and outstanding 
physico-chemical features. This synthetic route is based on a two-step hydrolysis/condensation reaction of (semi)metal alkoxides (such as tetramethoxysilane, tetraethoxysilane, aluminium isopropoxide, and titanium tetraisopropoxide), as schematized in Figure 3, which leads to the build-up of fully inorganic or hybrid organic-inorganic coatings at or near room temperature. The progress of the sol-gel reactions and the structure/morphology of the resulting oxidic networks are determined by several parameters: type of (semi)metal atom and alkyl/alkoxide groups, temperature and $\mathrm{pH}$, water/alkoxide ratio, reaction time, and presence of co-solvents [16].

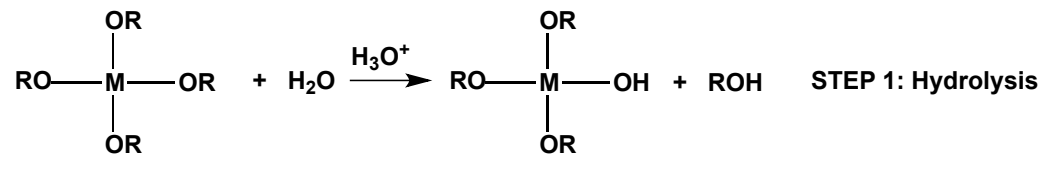

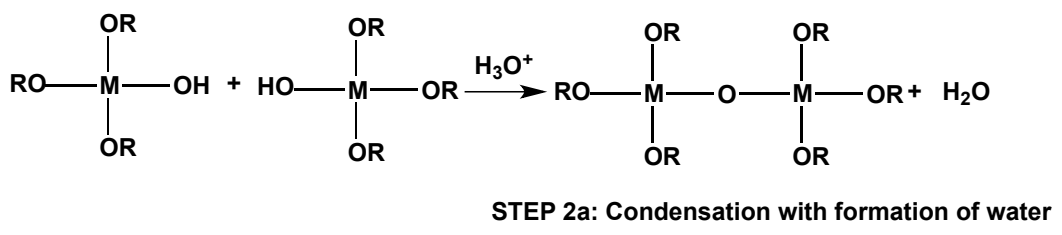

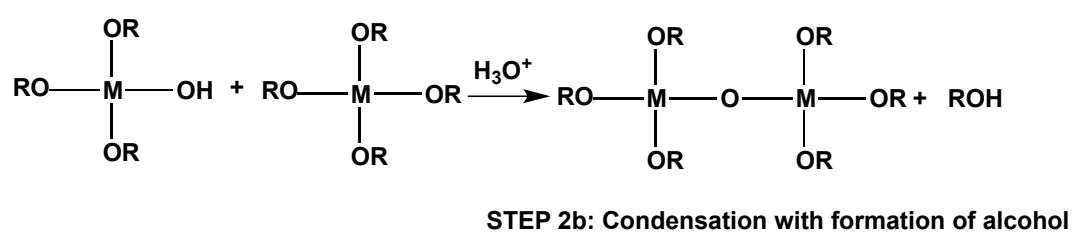

Figure 3. Scheme of a sol-gel process performed in acidic conditions ( $\mathrm{M}=($ semi)metal, such as $\mathrm{Si}, \mathrm{Ti})$.

As far as textiles are concerned, sol-gel processes have been effectively utilized for providing them with multifunctional features; more specifically, great attention has been devoted to the development of "smart" textiles. These later can show super-hydrophobic properties [17-19], antimicrobial [20-22] or UV radiation protection [23-25], dye fastness [26,27], biomolecule immobilisation [28], anti-wrinkle finishing [29], sensor characteristics [30,31], and photocatalytic features [32,33].

Although sol-gel methods have been utilized from the 1950s, their use in the design of flame-retardant textiles is quite recent and appealing: in fact, the ceramic phases formed on fabrics treated by sol-gel processes can exert a thermal shielding effect during the exposure of the fabrics to a flame or a heat source. As a consequence, the creation of a physical barrier to oxygen and heat transfer is achieved; at the same time, this barrier hinders the formation of volatile species that fuel the further textile degradation and favors the formation of a stable, carbonaceous, and inorganic residue [34,35].

Conversely, because of the limited thickness of the fabrics, the sol-gel derived architectures are able to exert just a partial shielding effect on the underlying substrate: this means that the flame-retardant features promoted by the sol-gel coatings are effective only when the ceramic phases work in synergistic or joint effects. These latter can be attained by combining the sol-gel coatings with other flame-retardant active species, such as phosphorus- and/or nitrogen-containing compounds, as will be discussed in the next paragraphs. Furthermore, the evolution of the sol-gel approach has led to the design of dual-cure processes, which can be utilized for obtaining hybrid organic-inorganic protective coatings [36], exploiting a photo-induced polymerization process followed by a thermal treatment for promoting the formation of sol-gel derived oxidic phases [37].

\subsection{Sol-Gel Inorganic Coatings}

First, the sol-gel approach has been commonly utilized for creating fully inorganic coatings on the underlying textiles. Sol-gel-derived silica coatings (thickness about $350 \mathrm{~nm}$ ) were exploited in order 
to decrease the flammability of regenerated cellulose fibers (namely, viscose) [38]. For this purpose, tetraethylorthosilicate (TEOS) was used as a precursor of the silica coating: increased thermal stability and fire resistance was found for the treated fibers. As compared with the untreated counterparts, the silica-coated viscose fibers showed a $20^{\circ} \mathrm{C}$ increase of both the first degradation step and flame combustion of volatile products, notwithstanding a $40{ }^{\circ} \mathrm{C}$ increase of the glowing combustion of the residue.

The same sol-gel-derived coating was also applied to cotton, polyester and cotton/polyester-rich blends, showing its capability to postpone the degradation reactions in nitrogen and air, as assessed by thermogravimetric analyses. Furthermore, the coatings were able to reduce the peak of the heat release rate (pkHRR) and to increase the time to ignition (TTI) during cone calorimetry tests [39].

Alternatively to TEOS, different precursors for silica or other oxidic phases, as well as the process parameters directly related to the resulting morphology of the sol-gel-derived coatings deposited on the fabrics have been thoroughly investigated. First, the effect of temperature and time of the thermal treatment and the precursor:water molar ratio on cotton flame retardancy was thoroughly investigated [40]. In particular, it was found that the most significant enhancements in cotton resistance to a heat flux were achieved by carrying out the sol-gel process at $80^{\circ} \mathrm{C}$ for $15 \mathrm{~h}$, keeping a 1:1 water:tetramethylortosilicate (TMOS) molar ratio. Indeed, cone calorimetry tests showed a 56\% increase of TTI and 15\% decrease of pkHRR: this behavior indicates that the sol-gel coating behaves like a thermal insulator, shifting the temperature at which degradation starts toward higher values and, at the same time, promoting the formation of a stable carbonaceous and inorganic residue as a consequence of cellulose dehydration [35].

The role of the number of hydrolysable alkoxy groups in the sol-gel precursor was investigated: in particular, the flame-retardant features of cotton treated with TMOS (having four methoxy groups) were compared with fabric treated with TEOS (bearing four ethoxy groups) and tetrabuthylorthosilicate (TBOS, having four buthoxy groups) [41]. The flame spread tests performed in a vertical configuration showed that, when a $\mathrm{C}_{3} \mathrm{H}_{8}$ flame was directly applied to the fabrics for $5 \mathrm{~s}$, the presence of even a small amount of silica coating was able to decrease the burning rate (from 2.50 to $1.45 \mathrm{~mm} / \mathrm{s}$ for untreated cotton and the TMOS-treated counterpart, respectively) and increase the total burning time, achieving, at the same time, a significant rise of the final residue (from 10, untreated fabric, to 35 and $48 \mathrm{wt} \%$, for TEOS- and TMOS-treated counterparts, respectively). In this way, it was possible to demonstrate that the shorter the precursor chain length is, the higher the reduction in flame spread. A similar reduction in flammability was observed in the cone calorimeter.

Furthermore, it was found that the burning behavior under the cone calorimeter strictly depends on the number of hydrolysable groups of the silica precursor: for this purpose, the combustion behavior of TEOS was compared with that of other alkoxysilanes, namely diethoxy(methyl)phenylsilane (DEMPhS), 3-aminopropyl trimethoxysilane (APTES), triethoxy(ethyl)silane (TEES), 1,4-bis(triethoxysilyl)benzene (bTESB) and 1,2-bis(triethoxysilyl)ethane (bTESE), for which the number of ethoxy groups ranges between 2 and 6 [42]. It is noteworthy that some of these molecules bear phenyl rings that may influence the overall fire performance of the treated fabrics. According to the cone calorimetry results, it was possible to demonstrate that: (i) alkoxysilanes having a low number of hydrolysable groups (i.e., two or three) behave like TEOS, notwithstanding the significant increase of smoke release and the nature/morphology of their final residues (very thin and incoherent products); (ii) the replacement of an amino group (APTES) with an alkyl chain (TEES) favors the formation of a compact and thicker residue; and (iii) bTESB and bTESE, having a high number of alkoxy functionalities, considerably modify the flammability of the fabrics (in particular, bTESB-treated cotton did not burn even after 10 flame applications of $5 \mathrm{~s}$ ) [42].

The influence of the precursor type and hence of the composition of the final coating was also investigated: cotton fabrics were treated with alumina, zirconia, or titania sol-gel-derived coatings, using aluminium isopropylate, tetraethylortho-zirconate, and tetraethylortho-titanate as starting precursors [43]. The silica coating turned out to provide the best flame retardancy performance 
(56\% TTI increase and 20\% pkHRR decrease in cone calorimetry tests), although alumina and titania coatings showed the best enhancement as far as abrasion resistance, assessed by Martindale tests, is considered. These findings suggested the design of a new sol-gel-derived silica coating containing alumina micro- or nano-particles, aiming at achieving an optimal balance between fire and tribological properties. In doing so, regardless of the size of the alumina particles, the new coatings deposited on cotton or cotton-linen fabrics were able to increase the abrasion resistance, as well as decrease the total burning time $(-45 \%)$ and increase the final residue of the treated fabrics $(+46 \%)$, as assessed by horizontal flame spread tests.

Similar results were obtained by Brzezinski and co-workers, who exploited the sol-gel method for coating cotton fabrics with a silica-alumina xerogel [44].

\subsection{Phosphorus-Doped Sol-Gel Coatings}

In order to further enhance the fire performance provided by sol-gel derived coatings, it is possible to exploit their synergistic or additive effects with other flame retardants, particularly referring to systems containing P or P and $\mathrm{N}$ elements. This can be achieved in three different ways, i.e., by utilizing alkoxysilane precursors that bear both silane and phosphate functional groups, by mixing an alkoxysilane precursor with a phosphoric acid source (which favors the dehydration of the fabric, hence promoting the formation of a stable carbonaceous and inorganic residue), or by incorporating an alkoxysilane precursor bearing both silane and phosphate functionalities into P- and N-containing compounds [45-48].

The first strategy was assessed by exploiting the simultaneous presence of $\mathrm{P}$ and $\mathrm{Si}$ elements in the same precursor, giving rise to the formation of hybrid organic-inorganic coatings. These latter act as promoters of the formation of a carbonaceous and inorganic residue, thanks to the presence of the phosphoric acid source, but also as thermal protective coatings (because of the inorganic ceramer). As an example, diethylphosphatoethyltriethoxysilane (DPTES) was utilized as a precursor for synthesizing a hybrid phosphorus-silicon organic-inorganic coating: more specifically, a multistep sol-gel process was exploited for obtaining hybrid phosphorus-doped silica architectures (from one to six layers) coated on cotton [45]. The obtained coatings were responsible for a decrease (up to $-43 \%$ ) of the burning time of the treated fabrics with respect to untreated counterparts, as indicated by the flameout values $(66,62$, and 80 vs. $116 \mathrm{~s}$, respectively, for one, three, and six layers vs. untreated cotton) measured in cone calorimetry tests. In addition, notwithstanding a decrease of TTI (10 vs. $18 \mathrm{~s}$, for six layers and untreated cotton, respectively), the sol-gel-derived coatings were able to limit the formation of volatile species, as indicated by the TSR values $\left(20,15\right.$, and 6 vs. $26 \mathrm{~m}^{2} / \mathrm{m}^{2}$, respectively, for one, three, and six layers vs. untreated cotton). These results were further improved through the optimization of the sol-gel reactions, involving a pre-hydrolysis step of the precursor [46], which allowed for enhancing the washing fastness of the treated fabrics (up to five washing cycles according to the ISO 6330 standard).

Next the possibility of developing synergistic effects between sol-gel-derived silica coatings, bearing both silane and phosphate functionalities, with $\mathrm{P}$ - and N-containing compounds, was explored. DPTES was first combined with APTES or APTES and a melamine-based resin (M) [47]: this combination gave rise to a significant increase of char yields, as assessed by thermogravimetric analyses in air (42 and $38 \mathrm{wt} \%$ for APTES/DPTES- and APTES/DPTES/MF-treated samples, respectively). Then, the $\mathrm{N}$-source was replaced with $\mathrm{N}, \mathrm{N}, \mathrm{N}^{\prime}, \mathrm{N}^{\prime}, \mathrm{N}^{\prime \prime}, \mathrm{N}^{\prime \prime}$-hexakis-methoxymethyl- $[1,3,5]$ triazine-2,4,6-triamine (MF) and the relative ratios of DPTES and MF were optimized [48]. It was found that the high char-forming character of the obtained coatings was able to protect the underlying cotton, reaching about $70 \mathrm{wt} \%$ of residue.

The occurrence of synergistic or additive effects was assessed by calculating Lewin's synergistic effectivity [49]: unlike hybrid phosphorus-doped silica coatings, further doped with N-containing molecules such as melamine or urea, for which additive effects were observed, synergism occurred when hybrid phosphorus-doped silica coatings were coupled with 1-hydroxyethane 1,1-diphosphonic acid [50]. 
Synergistic effects were also proven for sol-gel-derived coatings deposited on cotton fabrics and doped with different phosphoric acid sources, namely: aluminum phosphinate, a mixture of aluminum phosphinate, melamine poly(phosphate), zinc, and boron oxide, or $\mathrm{ZrP}$ nano-platelets [51]. In particular, it was possible to significantly increase TTI (from 14, for untreated cotton, to $40 \mathrm{~s}$ ) and the limiting oxygen index (LOI, from 19\%, for untreated cotton, to $30 \%$ ) simply by mixing the sol-gel precursor with $5 \mathrm{wt} \%$ of the abovementioned phosphorus-based compounds.

In addition, it was possible to verify the synergism occurring between phosphoric acid and sol-gel-derived silica architectures deposited on poly(acrylonitrile) (PAN) fibers [52]: these were not flammable when a flame was applied for $15 \mathrm{~s}$; besides, the treated fabrics showed an increase in washing fastness (up to 10 washing cycles according to TS EN ISO 105-C06-A1S).

A new combination of a functional sol-gel coating based on an amino silane ((3-trimethoxysilylpropyl) diethylenetriamine) and phenylphosphonic acid as a phosphorous-rich component was exploited for conferring flame-retardant properties on different textiles (namely, cotton, polyester, and a 65:35 cotton:polyester blend) [53]. The amount of sol-gel-derived coating was limited to about $10 \%$ with respect to the original textile in order to skip such negative side effects as high stiffness or unpleasant touch. In particular, the coated fabric samples achieved self-extinction in a small-scale flame test with surface and edge ignition (according to EN ISO 15025): this finding was ascribed to the formation of a protective layer, able to slow down combustion and lower the emission of fuel.

\subsection{Smoke Suppressant Effects Provided by Sol-Gel Coatings}

Apart from the flame-retardant enhancements provided by the ceramic phase that is formed during the flame or heat source application to fabrics treated by sol-gel-derived coatings, the recent scientific literature proves the need for the design of affective smoke suppressant to be combined with the sol-gel chemistry [54]. As a matter of fact, silica nano- or micro-particles or silica-based coatings easily obtained through sol-gel methods can be considered an example of an effective smoke suppressant system.

As reported in Table 2, it was possible to limit the TSR, $\mathrm{CO}$, and $\mathrm{CO}_{2}$ yields, as assessed by cone calorimetry tests, simply by adding such smoke suppressants as zinc borate, zinc acetate dehydrate, or zinc oxide, to the alkoxy precursor. Indeed, the presence of these additives reduced the release of smoke, $\mathrm{CO}$, and $\mathrm{CO}_{2}$ as compared to the cotton treated with the sol-gel-derived coating only [55].

Table 2. Cone calorimetry data of cotton fabrics treated with silica and smoke suppressants (adapted from [55]).

\begin{tabular}{ccccc}
\hline Sample & \multirow{2}{*}{ TSR $\left(\mathbf{m}^{2} / \mathbf{m}^{2}\right)$} & \multicolumn{2}{c}{ CO $(\mathbf{p p m})$} & \multicolumn{2}{c}{$\mathbf{C O}_{2}(\%)$} \\
\cline { 3 - 5 } & & 1st Peak & 2nd Peak & Peak \\
\hline Untreated cotton & 24 & 0.0011 & 0.0018 & 0.146 \\
Cotton treated with silica & 11 & 0.0005 & 0.0045 & 0.112 \\
Cotton treated with silica + Zinc oxide & 9 & 0.0002 & 0.0032 & 0.095 \\
Cotton treated with silica + Zinc acetate dihydrate & 18 & 0.0004 & 0.0040 & 0.110 \\
Cotton treated with Zinc borate & 17 & 0.0004 & 0.0040 & 0.108 \\
\hline
\end{tabular}

\subsection{Hybrid Organic-Inorganic Sol-Gel Coatings}

Some examples considering the exploitability of dual-cure processes, i.e., a photo-induced polymerization followed by a thermal treatment for performing sol-gel processes, for the obtainment of hybrid organic-inorganic coatings on fabrics, are reported in the literature [36,37]. These hybrid coatings are able to behave as thermal insulators, inhibiting the fabric combustion and hence providing enhanced flame-retardant features.

The flame-retardant features provided by a UV-curable formulation containing different quantities of TMOS (in between 30 and $80 \mathrm{wt} \%$ ) and methacryloyloxypropyltrimethoxysilane as a coupling agent were assessed [37]: indeed, this latter bears acrylic groups able to undergo the photopolymerization 
reaction, together with methoxy functionalities that can react with TMOS and the hydroxyl groups of cotton during the sol-gel process. As a result, a co-continuous hybrid coating is deposited on cotton. In particular, as assessed by flame spread tests performed in a horizontal configuration, the hybrid coating derived from the formulation containing $60 \mathrm{wt} \%$ TMOS was found to increase the total burning time and the final residue as well. Cone calorimetry tests further confirmed the protective role exerted by the coatings on the underlying fabric, showing an increase of TTI and of the final residue, despite an increase in the THR and pkHRR values.

A UV-curable system containing triglycidyl isocyanurate acrylate and tri(acryloyloxyethyl) phosphate was exploited for obtaining flame-retardant UV-cured coatings on cotton [56]. The flame retardancy of the treated fabrics was studied using a Micro-scale Combustion Calorimeter and limiting oxygen index: the flame-retardant coatings were found to lower the peak of heat release rate, the heat release capacity, and the total heat of combustion of the fabric, and to slightly increase the LOI values as compared with untreated cotton.

A two-step process was also exploited for obtaining flame-retardant and superhydrophobic cotton fabrics [57]. Ammonium dihydrogen phosphate and/or guanidine carbonate were first immobilized in a sol-gel coating based on aminopropyltriethoxysilane: these formulations provided remarkable flame-retardant properties to cotton. Hydrophobicity was achieved in a subsequent step, during which the flame-retardant fabric was further combined with a fluorofunctional silane or polysiloxane: as a result, flame-retarded hydrophobic fabrics were obtained. The occurrence of synergism between phosphorus- and nitrogen-containing compounds as well as organosilicon compounds was proven and allowed for achieving excellent flame-retardant features (i.e., an oxygen index as high as $71.6 \%$ and a $90 \%$ reduction in $Q_{\max }$ - maximum specific heat release rate assessed in Pyrolysis Combustion Flow Calorimetry tests-as compared with the unmodified fabric).

A combination of 9,10-dihydro-9-oxa-10-phosphaphenanthrene-10-oxide-modified vinyl trialkoxysilane (DOPO-VTS) and tetraethoxysilane was proposed as a sol-gel finishing for the preparation of flame-retardant polyamide-6 fibers [58]. The fabrics were treated with both DOPO-VTS and TEOS alone or in a mixture, at three different concentrations, using a pad-dry-cure method. Thermogravimetric analyses of the sol-gel-coated samples showed that the coatings anticipated PA6 decomposition, favoring, at the same time, the formation of char and ash. Vertical flame spread tests showed that, using high precursor concentrations in the coating, the residue completely stopped the melt dripping of the polymer.

A hybrid organic-inorganic coating containing phosphorus, silicon, and nitrogen elements, deposited on cotton fabrics through a sol-gel process, was also synthesized [59]. The hybrid coating was obtained through a sol-gel process, starting from 3-Aminopropyl triethoxysilane (APTES) and phenylphosphonic dichloride. The flammability and thermal degradation properties of the pristine and coated cotton fabrics were investigated by scanning electron microscopy, vertical flame spread tests, microscale combustion calorimetry, and thermogravimetric analysis coupled with Fourier transform infrared analysis. The sol-gel-derived coating was found to improve the thermal stability and burning behavior of cotton: regarding this latter, the fabrics treated with the hybrid coating achieved self-extinction immediately when the ignition source was removed. These findings were ascribed to the protective effect exerted by the deposited coating, which, upon heating, forms a ceramic layer on the fiber surface and favors the conversion of the underlying polymer into a thermally stable char, which effectively limits oxygen and heat transfer phenomena.

\section{Layer-by-Layer Coatings on Fabrics}

The layer-by-layer (LbL) method represents an alternative, reliable, and suitable method for the surface deposition of very thin architectures on different substrates, including metals, plastics, and textiles. The first example of the use of this technique appeared in 1966 [60], but its development dates from the early 1990s, as reported by Decher and co-workers [61]. 
Generally speaking, the LbL technique basically consists of an alternate adsorption of electrically oppositely charged chemical species on a selected substrate. Thus, it can be considered as a step-by-step coating build-up mainly based on electrostatic forces, although different interactions (e.g., hydrogen bonds [62,63], covalent bonds [64,65], donor-acceptor interactions [66], stereo-complex formation [67,68], etc.) can also be employed.

The LbL assembly exploiting electrostatic interactions is schematically shown in Figure 4: it basically necessitates the alternate immersion of the substrate into oppositely charged polyelectrolyte solutions (or dispersions); the concentration of these is very low (usually between 0.5 and $1 \mathrm{wt} \%$ ). As a result, an assembly of positively and negatively charged layers stacked on the substrate surface is achieved, exploiting a total surface charge reversal after each immersion step. The suitable reagents involved in the process can be chosen from a wide range of products: cationic or anionic polyelectrolytes, metallic or oxidic colloids, layered silicates, biomacromolecules, etc. As each of these categories can be further divided into subclasses, it is possible to design practically unlimited combinations of multilayered assemblies that can be chosen on the basis of the final application or required properties $[69,70]$.

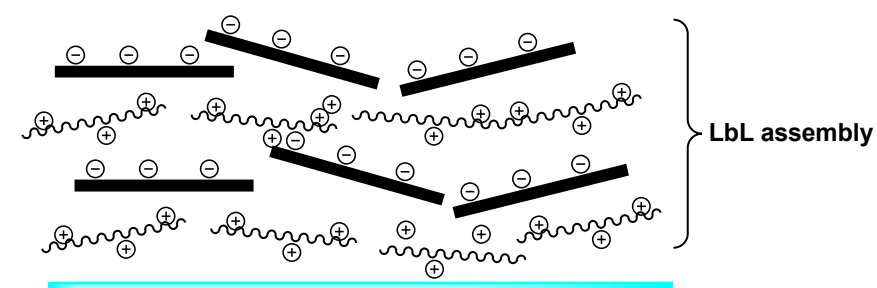

\section{FABRIC}

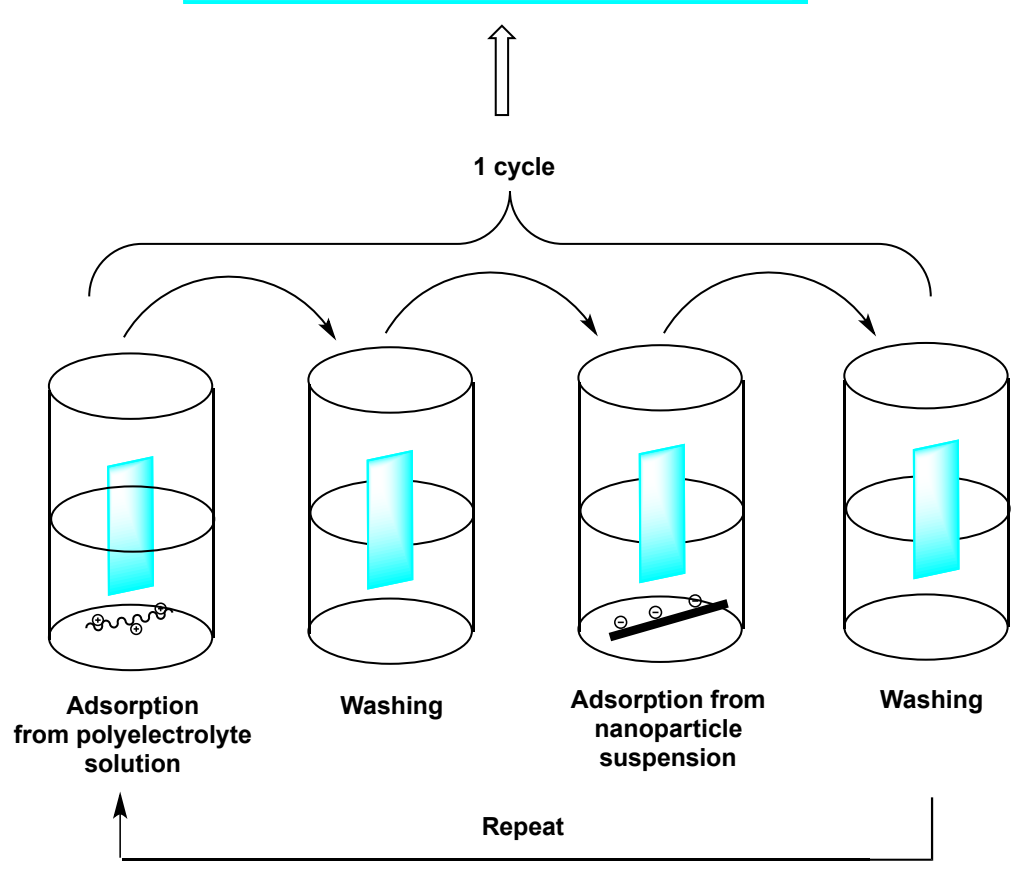

Figure 4. Scheme of the layer-by-layer (LbL) method.

The LbL method shows several benefits with respect to other more traditional thin film deposition approaches (such as plasma treatments and impregnation/exhaustion processes). In particular, the deposition occurs in "mild and environmentally-friendly conditions," i.e., at atmospheric pressure and room temperature, almost always using very diluted water solutions of polyelectrolytes or nanoparticle dispersions. In addition, it allows for the easy incorporation of functional species that turn out to specifically define the properties of the final assembly. 
The first applications of this method were directed to the build-up of coatings with extreme oxygen barrier properties [71-73]; it was also exploited for conferring anti-reflection [74], electrical conductivity [75], and antibacterial properties [76,77] to different kinds of substrates.

Up to now, most of the LbL coatings have been assembled on substrates having a high surface to bulk ratio, such as films and fabrics; in fact, these substrates show a high surface available for the coating with respect to the bulk. One of the most interesting uses of this approach refers to the possibility of providing flame-retardant features to textiles: hereafter, some recent advances concerning the application of the LbL method for the design of effective flame-retardant coatings on different fabric substrates will be thoroughly described.

\subsection{Fully Inorganic LbL Coatings}

The first examples of nanoparticle-based LbL coatings were devoted to the deposition of hybrid organic-inorganic structures consisting of a cationic polymer (branched polyethylenimine) in combination with anionic clays (i.e., montmorillonite or laponite) [78,79]. The designed LbL assemblies, applied on cotton fabrics, turned out to improve the thermal stability and the fire retardancy of the cellulosic substrate.

On the basis of these results, the LbL assembly has been modified, replacing the organic layers with inorganic ones, hence obtaining a fully inorganic coating. One of the first examples of this type of coating was made of positive alumina-coated silica $(10 \mathrm{~nm})$ and negative silica nanoparticles (10 or $40 \mathrm{~nm}$ ): this structure turned out to improve the flame-retardant features of cotton or polyester fabrics $[80,81]$. More specifically, the fully inorganic coatings were able to prevent the melt-dripping phenomena of polyester during vertical flame spread tests and to significantly improve the time to ignition in cone calorimetry experiments.

Spray-assisted layer-by-layer deposition was exploited for depositing silica/silica architectures, aimed at comparing the fire-retardant features achieved on cotton and polyester fabrics with those obtained by the dipping method. In particular, the horizontal spray showed the highest efficacy for obtaining a homogeneous surface deposition, as well as the best thermal protection effect during combustion $[82,83]$.

Some other nanoparticles have been utilized as components in fully inorganic LbL coatings $[84,85]$. In particular, the effects of Polyhedral Oligomeric Silsesquioxane (POSS ${ }^{\circledR}$, Hybrid Plastics Inc., Hattiesburg, MS, USA) salts bearing either positive or negative charges have been assessed: water-soluble OctaAmmonium POSS ((+)POSS) and OctaTMA POSS ((-)POSS) were employed as cationic and anionic components for thin film deposition from water. Aminopropyl silsesquioxane oligomer (AP) was also utilized as an alternative cationic species. With less than $8 \mathrm{wt} \%$ added to the total fabric weight, more than $12 \mathrm{wt} \%$ char remained after Micro cone calorimetry tests for the 20 bilayers of (+)POSS/(-)POSS-coated cotton. In addition, flame spread tests performed in a vertical configuration showed a decreased afterglow time, preserving, at the same time, the fabric weave structure and shape of the individual fibers [84].

Octapropylammonium-functionalized POSS ${ }^{\circledR}$ or alumina-coated silica nanoparticles have also been coupled with $\alpha$-Zirconium phosphate nanoplatelets and applied to polyester fabrics: an increased time to ignition, together with a decreased pkHRR, were found in cone calorimetry tests; furthermore, these indicated a reduction of smoke production rate, as well as of $\mathrm{CO}$ and $\mathrm{CO}_{2}$ yields [85].

\subsection{Intumescent LbL Coatings}

The design of intumescent LbL coatings has been carried out in order to further enhance the fire retardancy of the treated fabrics: indeed, because of the presence of the two types of layer, the intumescent assembly can provide a barrier effect (exerted by the inorganic layers) together with a charring effect (due to the reactive intumescent layers).

The first pioneering intumescent LbL coating for cotton fabrics was obtained by combining a poly(allylamine) (carbon source and blowing agent) with sodium phosphates (acid source) [86]. 
Vertical flame spread tests showed that the LbL-treated fabrics were able to achieve self-extinction when applied to cotton; in addition, cone calorimetry tests revealed the non-ignitability of the treated substrates.

Similar results were obtained when depositing up to 20 polyallylamine/montmorillonite bilayers on polyamide-6 [87]. In particular, cone calorimetry tests showed an excellent reaction to fire of the treated substrates, as indicated by the decrease (by more than $60 \%$ ) of pkHRR with respect to uncoated PA6. The formation of a continuous char and ash layer, which protects by limiting heat and mass transfer, was observed during the combustion and the thickness of the coating at the end of the combustion tests was doubled as compared to the initial thickness.

Chitosan (an efficient carbon source) was coupled with ammonium polyphosphate (acid source and blowing agent), obtaining LbL intumescent coatings on cotton-polyester blends [88]. The obtained assemblies were found to block the afterglow phenomena; coherent residues were obtained after flame spread tests in a horizontal configuration, notwithstanding a significant decrease of the combustion kinetics.

The same group designed an intumescent LbL coating consisting of quad-layers of poly(diallydimethylammonium chloride)/poly(acrylic acid)/poly(diallydime- thylammonium chloride)/ammonium polyphosphate, aimed at improving the fire retardancy of cotton and polyester fabrics $[89,90]$. The effective charring character of the LbL coatings was proved when cotton and polyester fabrics were exposed to high temperatures (up to $500^{\circ} \mathrm{C}$ ). In addition, the LbL assemblies were found to provide the fabrics with self-extinction, preventing polyester melt dripping phenomena and decreasing the heat-related parameters.

An intumescent-LbL coating consisting of polyethylenimine (carbon source) and ammonium polyphosphate (acid source and blowing agent) was designed and applied to ramie fabrics [91]. It was found that the assemblies containing a high ammonium polyphosphate concentration provide self-extinction in vertical flame spread tests to ramie fabrics.

The same group replaced ammonium polyphosphate with poly(vinylphosphonic acid) in the bilayer structure deposited on ramie fabrics [92]. Vertical flame spread tests showed that all the obtained coating fabrics were provided with lower after-flame time, and the residues preserved the original weave structure and fiber morphology well. In addition, microscale combustion calorimetry tests indicated that the designed assemblies could decrease the total heat release by as much as $66 \%$ and the heat release capacity by $76 \%$, with respect to those of the uncoated fabric.

These LbL assemblies were then doped with transition metal ions (namely, cupric and zinc ions) to further improve the flame-retardant properties of the ramie substrates [93]: the metal-ion-doped LbL coatings not only increased the residues but also retained the original weave structure and fiber morphology of ramie substrates; furthermore, they were responsible for a substantial decrease of the total burning time. These findings were likely due to the lower decomposition temperature of the flame-retardant LbL coating, as promoted by the presence of the doping ions. Lastly, the same research group performed LbL treatments on ramie fabrics, assembling up to 20 amino-functionalized carbon nanotubes and ammonium polyphosphate bilayers [94]. As assessed by cone calorimetry tests, the pkHRR and THR values of treated fabrics were found to progressively decrease with an increase in the number of deposited bilayers. These findings highlighted the importance of controlling the concentration of carbon nanotubes with respect to the build-up of a dense, thick scaffold and the corresponding absorption capacity toward ammonium polyphosphate.

An oligoallylamine and the phosphonated form were exploited as components in the design of intumescent LbL coatings [95]. In particular, LbL assemblies showed an improved thermal and thermo-oxidative stability: in fact, as assessed by thermogravimetric analyses, the coatings were able to produce very high residues $\left(37 \%\right.$ and $31 \%$ at $800{ }^{\circ} \mathrm{C}$, in inert and air atmosphere, respectively), indicating their possible exploitation in flame retardancy. Furthermore, different molecular weights and $\mathrm{pH}$ conditions adopted for the LbL deposition were investigated [96]: in particular, low molecular weights were found to promote an incomplete "island growth" coating, while high molecular weights 
promoted the formation of a homogeneous assembly (due to the increased charge density of the used phosphonated oligoallylamines), the thickness of which was determined by the adopted $\mathrm{pH}$. Both low and high molecular weight assemblies anticipated the decomposition temperatures of the cotton fabrics; only the coatings obtained at $\mathrm{pH} 10$ were able to delay the degradation of the substrate. The afterglow phenomena were suppressed after the application of the LbL assemblies and the best flammability results (referring to the reduction of the total burning time and the increase of the final residues) were obtained by using high molecular weight layers.

LbL coatings consisting of graphene oxide nanosheets coupled with a synthesized intumescent flame retardant-polyacrylamide (obtained by the copolymerizing of $\mathrm{N}^{1}$-(5,5-dimethyl-1,3,2dioxaphosphinyl-2-yl)-acrylamide and acrylamide) were designed and applied on cotton fabrics [97]. Thermogravimetric analyses showed that the obtained coatings were able to improve the thermal stability of the cellulosic substrate. Furthermore, cone calorimetry tests showed a decreased peak of heat release rate and higher time to ignition for the LbL-treated fabrics; finally, after combustion, the surface of the treated fabrics was covered by a layer of continuous and compact char.

Flame-retardant and self-healing superhydrophobic LbL coatings on cotton fabric were also designed, exploiting a solution-dipping method consisting of the sequential deposition of a trilayer of branched poly(ethylenimine), ammonium polyphosphate, and fluorinated-decyl polyhedral oligomeric silsesquioxane [98]. When directly exposed to a flame, the LbL coatings favored the formation of a porous char and ash layer, thanks to their intumescent character, hence providing self-extinction to the underlying fabrics. In addition, the fluorinated-decyl polyhedral oligomeric silsesquioxane was responsible for the creation of a superhydrophobic surface with a self-healing function. As a matter of fact, the coatings could repeatedly and autonomically restore the superhydrophobicity. Therefore it was possible to obtain a multifunctional cellulosic fabric, i.e., flame-retardant, waterproof, and self-cleaning (through a simple water rinsing process).

Anionic sodium phosphate (PSP) was combined with three polysiloxane materials containing different amine groups, comprising 35\%-45\% (trimethylammoniummethylphenythyl)-methyl siloxane, 55\%-65\% dimethyl siloxane copolymer chloride salt (QMS-435), aminoethylaminopropyl silsesquioxane-methylsilsesquioxane copolymer oligomer (WSA-7021), and aminopropyl silesquioxane oligomers (WSA-991) as positive polyelectrolyte polysiloxanes [99]. The coatings (ranging from five to 20 bilayers) were applied on a 1:1 nylon/cotton fabric blend using the layer-by-layer method. Twenty bilayers of PSP/WSA-9911 and PSP/WSA-7021 were found to provide self-extinction to the treated fabrics, which showed 1.5" char length. Conversely, the fabrics coated with 20 bilayers of PSP/QMS-435 were not able to extinguish the flame but showed slow burning rates across the fabric surface as compared to the untreated counterpart: this finding was ascribed to the difficulty in the formation of ammonia gas due to the lack of primary amino groups in the copolymer chloride salt. Finally, SEM analyses performed on the coated fabrics after vertical flame spread tests indicated the occurrence of swelling phenomena and the presence of an uneven surface texture.

Then, the LbL method was exploited for depositing nanostructured coatings based on ammonium polyphosphate and octapropyl ammonium polyhedral oligomeric silsesquioxane (POSS ${ }^{\circledR}$ ) on acrylic fabrics [100]. These assemblies, consisting of four or six bilayers, showed a homogeneous covering of the acrylic fibers, which, in turn, turned out to be well protected from the exposure to a $20 \mathrm{~mm}$ methane flame or $35 \mathrm{~kW} / \mathrm{m}^{2}$ heat flux. In particular, the melt dripping phenomenon was blocked and the combustion rate decreased. These findings were explained on the basis of the char-forming nature of APP, the ceramic thermal insulating barrier created by POSS, and the intimate contact taking place in the LbL structure between the two components.

Flame-retardant LbL intumescent coatings consisting of poly(allylamine), sodium polyphosphates , and $\mathrm{TiO}_{2}$ nanoparticles (5-15 quad-layers) were assembled, aimed at enhancing the flame-retardant properties of polyamide and polyester fabrics [101]. The thickness and topography of assemblies were investigated by ellipsometry and by atomic force microscopy techniques, respectively. In particular, the coatings showed a linear growth regime with a thickness of approximately $500 \mathrm{~nm}$ in the presence 
of 15 quad-layers. It is noteworthy that the morphology of the assemblies was found to strictly depend on the fabric substrate utilized for the deposition: in fact, as revealed by SEM analyses, the coatings were able to homogenously cover all external fibers of polyamide, while polyester fibers were covered only partially, showing the formation of aggregates. A pyrolysis combustion flow calorimeter was exploited for assessing the fire performance of the LbL assemblies on the two fabrics: unlike polyester, for which the effect was very limited, the coatings were able to efficiently reduce the peak of the heat release rate value for polyamide fabrics. These findings were ascribed to the different surface properties (i.e., wettability and porosity) between the fabrics investigated.

A relevant part of the research on LbL flame-retardant coatings performed during recent years has been devoted to the design of low-impact/highly environmentally friendly, renewable LbL intumescent coatings: these can provide enhanced flame-retardant features to the treated fabrics, keeping at the same time a green character.

One of the first examples involves the combination of chitosan (a carbon source, positively charged) with phytic acid (an acid source, negatively charged) on cotton fabrics [102]. In particular, the flame-retardant features provided by these LbL assemblies (30 bilayers) were investigated, modifying the $\mathrm{pH}$ of the aqueous deposition solutions. It was found that a change in the $\mathrm{pH}$ modifies the composition of the obtained LbL nanocoating: the assemblies created at $\mathrm{pH} 6$ were thicker and had $48 \mathrm{wt} \%$ phytic acid in the coating, while the thinnest films (with a phytic acid content of $66 \mathrm{wt} \%$ ) were obtained at $\mathrm{pH} 4$. In vertical flame spread tests, fabrics coated with high phytic acid content multilayers achieved self-extinction, while untreated cotton was entirely consumed. For the fabrics treated with pH 4 solutions, microcombustion calorimetry tests showed a remarkable decrease of pkHRR (by 60\%) and total heat release (by $76 \%$ ) as compared to the untreated cotton: these findings were ascribed to the high phosphorus content, which improves the intumescent behavior of the LbL coatings.

LbL coatings made of oppositely charged polyelectrolyte polyethyleneimine and ammonium polyphosphate were applied on ramie fabrics, using both a spray-assisted layer-by-layer technique and the conventional dipping method [103]. Thermogravimetric analysis showed that all the coated fabrics left two to three times as much residual char as did uncoated counterparts. Furthermore, the spraying method was more effective in providing thermal stability to the fabrics as compared with the dipping method. In addition, microscale combustion calorimetry and cone calorimetry tests demonstrated that the spray-assisted technique was also more effective in reducing both heat release capacity and pkHRR.

The layer-by-layer coating technique was also exploited to deposit a highly effective flame retardant (melamine polyphosphate) from water onto polyester-cotton fabrics [104]. The reaction between soluble melamine and sodium hexametaphosphate gave rise to a water-insoluble flame retardant during the coating procedure: the obtained nanocoating was able to provide self-extinction properties to polyester-cotton fabrics with only $12 \%$ relative coating weight. As assessed by vertical flame spread tests, pyrolysis combustion flow calorimetry, thermogravimetric analysis, and scanning electron microscopy, the excellent flame-retardant performance was explained by a combination of condensed and gas-phase activity.

A layer-by-layer intumescent flame-retardant coating, consisting of cationic chitosan and anionic ammonium polyphosphate, was applied on cotton fabrics [105]. Twenty bilayers were found to significantly reduce the burning time and effectively control the fire propagation with only $27 \mathrm{~mm}$ damaged length in the horizontal direction. Despite the residual char of the coated fabric after flame spread tests performed in a vertical configuration, the textile structure remained perfectly intact and had substantial mechanical strength due to the protection of the deposited coating. Several bubbles formed on the surface of the fibers with 20 bilayer coatings after burning, showing the occurrence of an intumescent effect. Finally, microcone calorimetry tests showed a decrease in both pkHRR and THR for the coated fabrics, as compared with the uncoated counterparts.

The same group [106] proposed a polyhexamethylene guanidine phosphate-ammonium polyphosphate LbL assembly for providing cotton fabric with flame-retardant and antimicrobial properties. Vertical flame spread tests demonstrated that the deposited LbL coating was able to reduce 
the burning time, suppress the afterglow, and increase the residue, while keeping intact the textile structure. Finally, antimicrobial tests confirmed that the designed coatings have effective antimicrobial action against Escherichia coli and Staphylococcus aureus.

Similar intumescent results were obtained by replacing ammonium polyphosphate with potassium alginate (PA) extracted from seaweed: thus it was possible to exploit the intumescent effect of environmentally friendly antimicrobial polyhexamethylene guanidine phosphate with the green character of potassium alginate [107]. First, a linear growth of the LbL assemblies was assessed by means of attenuated total reflectance infrared spectroscopy analysis. In addition, thermogravimetric results showed the formation of higher residue char on the coated fabrics, as compared to the untreated counterparts, owing to the char-forming nature of the LbL assembly. Microcombustion tests indicated a remarkable decrease of the pkHRR and THR of the treated fabric samples; furthermore, the afterglow phenomenon was suppressed in the presence of the coating. Finally, the antimicrobial effect on Escherichia coli and Staphylococcus aureus of the LbL coatings was demonstrated: the coated fabric could inactivate 100\% Escherichia coli and Staphylococcus aureus in 5 and 30 min, respectively.

Another environmentally friendly LbL intumescent coating, consisting of starch and polyphosphoric acid layers, was applied to cotton fabrics, which were plasma pre-activated before depositing the LbL assembly [108]. Up to four bilayers were built up on the fabric surface: the obtained LbL coatings were homogeneous even at a low number of deposition steps and improved the char-forming ability of cotton, almost doubling the char formed at high temperatures, as evaluated by thermogravimetric analyses. Two bilayers were able to achieve self-extinction during flame spread tests performed in a horizontal configuration. Furthermore, cone calorimetry tests revealed a remarkable decrease (up to $40 \%$ ) of THR during combustion, indicating the highly fireproof character of the designed coatings.

In addition, DNA (deoxyribonucleic acid)-containing LbL coatings have been designed and thoroughly investigated, aiming to assess the effect of this biomacromolecule on the flame-retardant features of the treated fabrics. DNA can be considered an all-in-one intumescent system [109,110]: in fact, the phosphate groups can act as an acid source, the deoxyribose units can work as a carbon source, and the nitrogen-containing bases may release a blowing agent such as ammonia. Prior to its use as a component in LbL assemblies, this biomacromolecule has already been exploited as a finishing treatment for cotton, providing it with self-extinction in horizontal flame spread tests and decreasing the combustion kinetics [109].

DNA (negatively charged) was combined with chitosan layers (positively charged) on cotton, thus obtaining up to 20 bilayers [111]. In the presence of chitosan, DNA layers were found to favor the char-forming character of chitosan. Infrared spectroscopy and SEM analyses indicated an exponential growth of the LbL coatings. These provided cotton fabrics with self-extinction in horizontal flame spread tests and increased LOI values from $18 \%$ (uncoated cotton) to $24 \%$ (cotton treated with 20 bilayers); furthermore, cone calorimetry tests showed a decrease of HRR by $40 \%$ and an increase of the final residue for the fabrics treated with 20 bilayers.

\subsection{Hybrid Organic-Inorganic LbL Coatings}

As mentioned in the previous section, it is possible to use the LbL assembly in order to deposit coatings that combine the barrier effect provided by the presence of the nanoparticles with the intumescent properties; in this way, hybrid coatings can be designed and obtained. The most important goal of a hybrid LbL coating is to improve the protection offered by the char obtained from the intumescent layers of the deposited assembly. By exploiting the presence of the inorganic layers that can give rise to a ceramic phase, we are able to significantly enhance the overall fire-retardant properties of the treated substrate.

The first example of an LbL hybrid coating consisted of chitosan, ammonium polyphosphate, and silica nanoparticles (bearing positive or negative charges) deposited on cotton-PET blends [112]. It was found that the morphology and the physical stability of the assemblies play a key role in 
determining the fire performance of the treated substrates. This was strictly correlated with the development of a homogeneous and coherent LbL coating.

LbL coatings consisting of poly(acrylic acid) and amino-functionalized montmorillonite nanoplatelets were designed and applied on cotton fabrics [113]. After the LbL deposition, the fabrics were found to decrease the kinetics of the combustion process. At the same time, the SEM pictures of the residues after combustion tests showed the formation of a blown charred structure embedding montmorillonite nanoplatelets.

The same nanoparticles were exploited as a suitable layer in LbL assemblies with dimethyl diallyl ammonium chloride-allyl glycidyl ether deposited on cotton [114]: a layer-by-layer modified method (comprising a dipping step, and subsequent padding, drying, and curing) was used. The thermal properties and burning behavior of the treated fabrics were assessed through TGA, vertical flame spread tests, and oxygen index tests. The LbL assemblies were found to increase the residue formed at high temperature, as assessed by thermogravimetric analyses; vertical flame spread tests showed an increase of the total burning time and of the final residue as well. LOI values slightly increased in the presence of the deposited coatings.

A renewable and low-impact assembly for enhancing the flame retardancy of cotton fabrics was developed [115]: semi-biobased layers, comprising phosphorylated poly (vinyl alcohol) (as negatively charged layer) and chitosan (positively charged layer), were deposited on the fabric. The cotton fabrics treated with 30 bilayers provided self-extinction of the flame in flame spread tests performed in a vertical configuration. Furthermore, microscale combustion calorimetry tests showed a decrease in pkHRR and THR for all the LbL-treated cotton fabrics with respect to the untreated cotton.

The simultaneous improvement of flame retardancy and physiological comfort of polyester clothing fabrics was also investigated [116]. Polyester fabrics were LbL-coated with branched polyethylenimine and sodium montmorillonite; the effect of the number of bilayers on thermo-oxidative properties and flame retardancy behavior as well as physiological comfort (in terms of wicking, moisture management, and air permeability) was thoroughly assessed. The obtained results proved the efficiency of the deposited hybrid coatings in improving both facets.

Washing fastness is one of the most challenging issues of LbL coatings. Indeed, these assemblies are waterborne and hence usually exhibit a low resistance to washing cycles. As a matter of fact, the concurrent presence of water and surfactants in the washing medium determines a weakening of the electrostatic interactions taking place between the deposited layers, hence leading to the collapse of the LbL assembly. A few attempts have been recently carried out in order to overcome this problem, as will be described in the following. However, the current strategies addressing this problem are mainly based on the use of thermal- or UV-curable organic layers, which limits the potential of the LbL coatings as it reduces the number of suitable (reactive) components in the designed assemblies. First, the weak washing fastness was addressed by $\mathrm{LbL}$ architectures consisting of sodium montmorillonite and poly(N-benzyloxycarbonyl-3,4-dihydroxyphenylalanine) layers coated on polyimide fabrics [117]. In vertical flame testing, these coatings improved the fabric flammability properties and were able to maintain performance after 20 standard washing cycles.

Another attempt coupled the LbL method with an UV-curing process [118]. More specifically, three bilayers consisting of an anionic UV-curable aliphatic acrylic polyurethane latex doped with a phosphorus-based flame retardant (namely, ammonium polyphosphate, APP) and chitosan were deposited on cotton fabrics by dipping [119]. Then, the obtained LbL architecture was exposed to UV radiation: the formation of a thin coating, due to the intimate contact with chitosan within the obtained UV-cured network, was demonstrated. Such LbL coatings showed flame-retardant features together with an improved washing fastness: in fact, the treated fabrics achieved self-extinction after a washing cycle performed in water at $65^{\circ} \mathrm{C}$ for $1 \mathrm{~h}$.

Another challenging issue of the LbL approach concerns the possibility of setting up a continuous process, which is reasonably exploitable for commercial and industrial applications. This issue was addressed by designing a continuous layer-by-layer system in order to deposit polymer-clay 
nanocoatings on cotton fabrics and improve their fire-proof features. In particular, alternating layers of positively charged branched polyethylenimine with urea and diammonium phosphate and negatively charged clay nanoparticles were continuously applied to the fabrics via up to 50 bilayers, in a single process, skipping the rinsing step [120]. The new deposition method was able to provide the cellulosic substrate with an improved thermal stability, increased TTI, and decreased HRR, as assessed by thermogravimetric analyses and cone calorimetry tests.

\section{Conclusions}

This review has demonstrated the importance, feasibility, and reliability of such surface engineering strategies as sol-gel processes and layer-by-layer depositions. Among the different methods that can be successfully exploited for obtaining fire-retardant textiles, sol-gel and layer-by-layer represent an easy and affordable way to design well-controlled (nano)architectures on the fabric surface, i.e., the most critical region exposed to a flame or to a heat source. Despite the interest these two approaches have garnered, especially from a scientific/academic point of view, they are still a challenge to scale up to an industrial level, hence a commercial valorization/exploitation has to be considered. Furthermore, the resistance to washing cycles of the LbL coatings, which are mostly based on electrostatic interactions, is rather low, despite the efforts recently carried out to address this problem. However, the scientific research that has been performed so far seems to indicate a real possibility of further developing and optimizing these surface-engineered approaches, leading beyond their current limitations.

Acknowledgments: European COST Action "Sustainable flame retardancy for textiles and related materials based on nanoparticles substituting conventional chemicals", FLARETEX (MP1105) is gratefully acknowledged.

Conflicts of Interest: The author declares no conflict of interest.

\section{References}

1. Brushlinsky, N.N.; Ahrens, M.; Sokolov, S.V.; Wagner, P. World Fire Statistics; International Association of Fire and Rescue Service (CTIF): Berlin, Germany, 2015.

2. World Fire Statistics: Information Bulletin of the World Fire Statistics Centre; World Fire Statistics Centre: Geneva, Switzerland, 2014; Volume 29.

3. Bourbigot, S. Flame retardancy of textiles e new approaches. In Advances in Fire Retardant Materials; Horrocks, A.R., Price, D., Eds.; Woodhead Publishing: Cambridge, UK, 2008; pp. 9-40.

4. Weil, E.D.; Levchik, S.V. Flame retardants in commercial use or development for textiles. J. Fire Sci. 2008, 26, 243-281. [CrossRef]

5. Neisius, M.; Stelzig, T.; Liang, S.; Gaan, S. Flame retardant finishes for textiles. In Functional Finishes for Textiles; Paul, R., Ed.; Woodhead Publishing: Cambridge, UK, 2015; pp. 429-461.

6. Horrocks, A.R.; Price, D. Fire Retardant Materials; Woodhead Publishing: Cambridge, UK, 2000.

7. Horrocks, A.R. Flame retardant challenges for textiles and fibers: New chemistry versus innovatory solutions. Polym. Degrad. Stab. 2011, 96, 377-392. [CrossRef]

8. Visakh, P.M.; Arao, Y. Flame Retardants. Polymer Blends, Composites and Nanocomposites; Springer International Publishing: Cham, Switzerland, 2015.

9. Cai, Y.; Wu, N.; Wei, Q.; Zhang, K.; Xu, Q.; Gao, W.; Song, L.; Hu, Y. Structure, surface morphology, thermal and flammability characterizations of polyamide6/organic-modified Fe-montmorillonite nanocomposite fibers functionalized by sputter coating of silicon. Surf. Coat. Technol. 2008, 203, 264-270. [CrossRef]

10. Pappas, D. Status and potential of atmospheric plasma processing of materials. J. Vac. Sci. Technol. A Vac. Surf. Films 2011, 29, 020801-020817. [CrossRef]

11. Dineff, P.; Gospodinova, D.; Kostova, L.; Vladkova, L.; Chen, E. Plasma-aided surface technology for modification of materials referred to fire protection. Probl. At. Sci. Technol. 2008, 6, 198-200.

12. Tata, J.; Alongi, J.; Frache, A. Optimization of the procedure to burn textile fabrics by cone calorimeter: Part II. Results on nanoparticle-finished polyester. Fire Mater. 2012, 36, 527-536. [CrossRef] 
13. Carosio, F.; Alongi, J.; Frache, A. Influence of surface activation by plasma and nanoparticle adsorption on the morphology, thermal stability and combustion behavior of PET fabrics. Eur. Polym. J. 2011, 47, 893-902. [CrossRef]

14. Alongi, J.; Tata, J.; Frache, A. Hydrotalcite and nanometric silica as finishing additives to enhance the thermal stability and flame retardancy of cotton. Cellulose 2011, 18, 179-190. [CrossRef]

15. Horrocks, A.R.; Nazaré, S.; Masood, R.; Kondola, B.; Price, D. Surface modification of fabrics for improved flash-fire resistance using atmospheric pressure plasma in the presence of a functionalized clay and polysiloxane. Polym. Adv. Technol. 2011, 22, 22-29. [CrossRef]

16. Cireli, A.; Onar, N.; Ebeoglugil, M.F.; Kayatekin, I.; Kutlu, B.; Culha, O.; Celik, E. Development of Flame Retardancy Properties of New Halogen-Free Phosphorous Doped $\mathrm{SiO}_{2}$ Thin Films on Fabrics. J. Appl. Polym. Sci. 2007, 105, 3747-3756. [CrossRef]

17. Mahltig, B.; Böttcher, H. Modified silica sol coatings for water-repellent textiles. J. Sol-Gel Sci. Technol. 2003, 27, 43-52. [CrossRef]

18. Yu, M.; Gu, G.; Meng, W.D.; Qing, F.L. Superhydrophobic cotton fabric coating based on a complex layer of silica nanoparticles and perfluorooctylated quaternary ammonium silane coupling agent. Appl. Surf. Sci. 2007, 253, 3669-3673. [CrossRef]

19. Xue, C.H.; Ji, S.T.; Chen, H.Z.; Wang, M. Superhydrophobic cotton fabrics prepared by sol-gel coating of $\mathrm{TiO}_{2}$ and surface hydrophobization. Sci. Technol. Adv. Mater. 2008, 9, 1-5. [CrossRef]

20. Mahltig, B.; Fiedler, D.; Böttcher, H. Antimicrobial sol-gel coatings. J. Sol-Gel Sci. Technol. 2004, 32, $219-222$. [CrossRef]

21. Mahltig, B.; Haufe, F.; Böttcher, H. Functionalisation of textiles by inorganic sol-gel coatings. J. Mater. Chem. 2005, 15, 4385-4398. [CrossRef]

22. Xing, Y.J.; Yang, X.J.; Dai, J.J. Antimicrobial finishing of cotton textile based on water glass by sol-gel method. J. Sol-Gel Sci. Technol. 2007, 43, 187-192. [CrossRef]

23. Mahltig, B.; Böttcher, H.; Rauch, H.; Dieckman, U.; Nitsche, R.; Fritz, T. Optimized UV protecting coatings by combination of organic and inorganic UV absorbers. Thin Solid Films 2005, 485, 108-114. [CrossRef]

24. Abidi, N.; Hequet, E.; Tarimala, S.; Dai, L.L. Cotton fabric surface modification for improved UV radiation protection using sol-gel process. J. Appl. Polym. Sci. 2007, 104, 111-117. [CrossRef]

25. Xing, X.J.; Ding, J. UV photo-stabilization of tetrabutyl titanate for aramid fibers via sol-gel surface modification. J. Appl. Polym. Sci. 2007, 103, 3113-3119. [CrossRef]

26. Mahltig, B.; Textor, T. Combination of silica sol and dyes on textiles. J. Sol-Gel Sci. Technol. 2006, 39, 111-118. [CrossRef]

27. Cireli, A.; Onar, N. Leaching and fastness behavior of cotton fabrics dyed with different type of dyes using sol-gel process. J. Appl. Polym. Sci. 2008, 109, 97-105.

28. Li, F.Y.; Xing, Y.J.; Ding, X.; Zu, Y. Immobilization of papain on cotton fabric by sol-gel method. Enzyme Microb. Technol. 2007, 40, 1692-1697. [CrossRef]

29. Huang, K.S.; Nien, Y.H.; Hsiao, K.C.; Chang, Y.S. Application of $\mathrm{DMEU} / \mathrm{SiO}_{2}$ gel solution in the antiwrinkle finishing of cotton fabrics. J. Appl. Polym. Sci. 2006, 102, 4136-4143. [CrossRef]

30. Caldara, M.; Colleoni, C.; Guido, E.; Re, V.; Rosace, G. Development of a textileoptoelectronic pH meter based on hybrid xerogel doped with methyl red. Sens. Actuators B 2012, 171, 1013-1021. [CrossRef]

31. Van der Schueren, L.; De Clerck, K.; Brancatelli, G.; Rosace, G.; Van Damme, E.; De Vos, W. Novel cellulose and polyamide halochromic textile sensors based on the encapsulation of methyl red into a sol-gel matrix. Sens. Actuators B 2012, 162, 27-34. [CrossRef]

32. Moafi, H.F.; Shojaie, A.F.; Zanjanchi, M.A. Flame-retardancy and photocatalytic properties of cellulosic fabric coated by nano-sized titanium dioxide. J. Therm. Anal. Calorim. 2011, 104, 717-724. [CrossRef]

33. Colleoni, C.; Massafra, M.R.; Rosace, G. Photocatalytic properties and optical characterization of cotton fabric coated via sol-gel with non-crystalline $\mathrm{TiO}_{2}$ modified with poly(ethylene glycol). Surf. Coat. Technol. 2012, 207, 79-88. [CrossRef]

34. Alongi, J.; Malucelli, G. State of the art and perspectives on sol-gel derived hybrid architectures for flame retardancy of textiles. J. Mater. Chem. 2012, 22, 21805-21809. [CrossRef]

35. Alongi, J.; Malucelli, G. Thermal degradation of cellulose and cellulosic substrates. In Reactions and Mechanisms in Thermal Analysis of Advanced Materials; Tiwari, A., Raj, B., Eds.; John Wiley \& Sons, Inc.: Hoboken, NJ, USA, 2015; pp. 301-332. 
36. Malucelli, G. Hybrid organic/inorganic coatings through dual-cure processes: State of the art and perspectives. Coatings 2016, 6, 1-11. [CrossRef]

37. Alongi, J.; Ciobanu, M.; Malucelli, G. Cotton fabrics treated with hybrid organic-inorganic coatings obtained through dual-cure processes. Cellulose 2011, 18, 1335-1348. [CrossRef]

38. Hribernik, S.; Smole, M.S.; Kleinschek, K.S.; Bele, M.; Jamink, J.; Gaberscek, M. Flame retardant activity of $\mathrm{SiO}_{2}$-coated regenerated cellulose fibers. Polym. Degrad. Stab. 2007, 92, 1957-1965. [CrossRef]

39. Alongi, J.; Ciobanu, M.; Carosio, F.; Tata, J.; Malucelli, G. Thermal stability and flame retardancy of polyester, cotton and relative blend textile fabrics subjected to sol-gel treatments. J. Appl. Polym. Sci. 2011, 119, 1961-1969. [CrossRef]

40. Alongi, J.; Ciobanu, M.; Malucelli, G. Sol-gel treatments for enhancing flame retardancy and thermal stability of cotton fabrics: Optimization of the process and evaluation of durability. Cellulose 2011, 18, 167-177. [CrossRef]

41. Alongi, J.; Ciobanu, M.; Malucelli, G. Sol-gel treatments on cotton fabrics for improving thermal and flame stability: Effect of the structure of the alkoxysilane precursor. Carbohydr. Polym. 2012, 87, 627-635. [CrossRef]

42. Alongi, J.; Ciobanu, M.; Malucelli, G. Thermal stability, flame retardancy and mechanical properties of cotton fabrics treated with inorganic coatings synthesized through sol-gel processes. Carbohydr. Polym. 2012, 87, 2093-2099. [CrossRef]

43. Alongi, J.; Malucelli, G. Thermal stability, flame retardancy and abrasion resistance of cotton and cotton-linen blends treated by sol-gel silica coatings containing alumina micro- or nano-particles. Polym. Degrad. Stab. 2013, 98, 1428-1438. [CrossRef]

44. Brzezinski, S.; Kowalczyk, D.; Borak, B.; Jasiorski, M.; Tracz, A. Applying the sol-gel method to the deposition of nanocoats on textiles to improve their abrasion resistance. J. Appl. Polym. Sci. 2012, 125, 3058-3067. [CrossRef]

45. Alongi, J.; Colleoni, C.; Malucelli, G.; Rosace, G. Hybrid phosphorus-doped silica architectures derived from a multistep sol-gel process for improving thermal stability and flame retardancy of cotton fabrics. Polym. Degrad. Stab. 2012, 97, 1334-1344. [CrossRef]

46. Alongi, J.; Colleoni, C.; Rosace, G.; Malucelli, G. The role of pre-hydrolysis on multistep sol-gel processes for enhancing the flame retardancy of cotton. Cellulose 2013, 20, 525-535. [CrossRef]

47. Brancatelli, G.; Colleoni, C.; Massafra, M.R.; Rosace, G. Effect of hybrid phosphorus-doped silica thin films produced by sol-gel method on the thermal behavior of cotton fabrics. Polym. Degrad. Stab. 2011, 96, 483-490. [CrossRef]

48. Alongi, J.; Colleoni, C.; Rosace, G.; Malucelli, G. Thermal and fire stability of cotton fabrics coated with hybrid phosphorus-doped silica films. J. Therm. Anal. Calorim. 2012, 110, 1207-1216. [CrossRef]

49. Lewin, M. Synergism and catalysis in flame retardancy of polymers. Polym. Adv. Technol. 2001, 12, $215-222$. [CrossRef]

50. Alongi, J.; Colleoni, C.; Rosace, G.; Malucelli, G. Phosphorus- and nitrogen-doped silica coatings for enhancing the flame retardancy of cotton: Synergisms or additive effects? Polym. Degrad. Stab. 2013, 98, 579-589. [CrossRef]

51. Alongi, J.; Ciobanu, M.; Malucelli, G. Novel flame retardant finishing systems for cotton fabrics based on phosphorus-containing compounds and silica derived from sol-gel processes. Carbohydr. Polym. 2011, 85, 599-608. [CrossRef]

52. Yaman, N. Preparation and flammability properties of hybrid materials containing phosphorous compounds via sol-gel process. Fibers Polym. 2009, 10, 413-418. [CrossRef]

53. Kappes, R.S.; Urbainczyk, T.; Artz, U.; Textor, T.; Gutmann, J.S. Flame retardants based on amino silanes and phenylphosphonic acid. Polym. Degrad. Stab. 2016, 129, 168-179. [CrossRef]

54. Dasari, A.; Yu, Z.Z.; Cai, G.P.; Mai, Y.W. Recent developments in the fire retardancy of polymeric materials. Prog. Polym. Sci. 2013, 38, 1357-1387. [CrossRef]

55. Alongi, J.; Malucelli, G. Cotton fabrics treated with novel oxidic phases acting as effective smoke suppressants. Carbohydr. Polym. 2012, 90, 251-260. [CrossRef] [PubMed]

56. Xing, W.; Jie, G.; Song, L.; Hu, S.; Lv, X.; Wang, X. Flame retardancy and thermal degradation of cotton textiles based on UV-curable flame retardant coatings. Thermochim. Acta 2011, 513, 75-82. [CrossRef] 
57. Przybylak, M.; Maciejewski, H.; Dutkiewicz, A.; Wesołek, D.; Władyka-Przybylak, M. Multifunctional, strongly hydrophobic and flame-retarded cotton fabrics modified with flame retardant agents and silicon compounds. Polym. Degrad. Stab. 2016, 128, 55-64. [CrossRef]

58. Sehic, A.; Tomsic, B.; Jerman, I.; Vasiljevic, J.; Medved, J.; Simoncic, B. Synergistic inhibitory action of P- and Si-containing precursors in sol-gel coatings on the thermal degradation of polyamide 6. Polym. Degrad. Stab. 2016, 128, 245-252. [CrossRef]

59. Liu, Y.; Pan, Y.T.; Wang, X.; Acuña, P.; Zhu, P.; Wagenknecht, U.; Heinrich, G.; Zhang, X.Q.; Wang, R.; Wang, D.-Y. Effect of phosphorus-containing inorganic-organic hybrid coating on the flammability of cotton fabrics: Synthesis, characterization and flammability. Chem. Eng. J. 2016, 294, 167-175. [CrossRef]

60. Iler, R.K. Multilayers of colloidal particles. J. Colloid Interface Sci. 1966, 21, 569-594. [CrossRef]

61. Decher, G.; Hong, J.D. Buildup of ultrathin multilayer films by a self-assembly process: II. Consecutive adsorption of anionic and cationic bipolar amphiphiles on charged surfaces. Makromol. Chem. Macromol. Symp. 1991, 46, 321-327. [CrossRef]

62. Shimazaki, Y.; Mitsuishi, M.; Ito, S.; Yamamoto, M. Preparation and Characterization of the Layer-by-Layer Deposited Ultrathin Film Based on the Charge-Transfer Interaction in Organic Solvents. Langmuir 1998, 14, 2768-2773. [CrossRef]

63. Stockton, W.B.; Rubner, M.F. Molecular-Level Processing of Conjugated Polymers. 4. Layer-by-Layer Manipulation of Polyaniline via Hydrogen-Bonding Interactions. Macromolecules 1997, 30, 2717-2725. [CrossRef]

64. Fang, M.M.; Kaschak, D.M.; Sutorik, A.C.; Mallouk, T.E. A “Mix and Match” Ionic-Covalent Strategy for Self-Assembly of Inorganic Multilayer Films. J. Am. Chem. Soc. 1997, 119, 12184-12191. [CrossRef]

65. Ichinose, I.; Kawakami, T.; Kunitake, T. Alternate Molecular Layers of Metal Oxides and Hydroxyl Polymers Prepared by the Surface Sol-Gel Process. Adv. Mater. 1998, 10, 535-539. [CrossRef]

66. Wang, X.; Naka, K.; Wang, C.; Itoh, H.; Uemura, T.; Chujo, Y. Layer-by-Layer Films Based on Charge Transfer Interaction of $\pi$-Conjugated Poly(dithiafulvene) and Incorporation of Gold Nanoparticles into the Films. J. Appl. Polym. Sci. 2007, 103, 1608-1615. [CrossRef]

67. Serizawa, T.; Hamada, K.; Kitayama, T.; Katsukawa, K.; Hatada, K.; Akashi, M. Stepwise Assembly of Isotactic Poly(Methyl Methacrylate) and Syndiotactic Poly(Methacrylic Acid) on a Substrate. Langmuir 2000, 16, 7112-7115. [CrossRef]

68. Serizawa, T.; Yamashita, H.; Fujiwara, T.; Kimura, Y.; Akashi, M. Stepwise Assembly of Enantiomeric Poly(lactide)s on Surfaces. Macromolecules 2001, 34, 1996-2001. [CrossRef]

69. Malucelli, G. Layer-by-Layer nanostructured assemblies for the fire protection of fabrics. Mater. Lett. 2016, 166, 339-342. [CrossRef]

70. Malucelli, G.; Carosio, F.; Alongi, J.; Fina, A.; Frache, A.; Camino, G. Materials Engineering For Surface-Confined Flame Retardancy. Mater. Sci. Eng. R Rep. 2014, 84, 1-20. [CrossRef]

71. Jang, W.S.; Rawson, I.; Grunlan, J.C. Layer-by-layer assembly of thin film oxygen barrier. Thin Solid Films 2008, 516, 4819-4825. [CrossRef]

72. Grunlan, J.C.; Jang, W.-S. Layer-by-layer assembly of nano brick walls: Tailoring film growth and gas permeability. ACS Polym. Prepr. 2008, 49, 342.

73. Priolo, M.A.; Gamboa, D.; Grunlan, J.C. Transparent clay-polymer nano brick wall assemblies with tailorable oxygen barrier. ACS Appl. Mater. Interfaces 2010, 2, 312-320. [CrossRef]

74. Podsiadlo, P.; Sui, L.; Elkasabi, Y.; Burgardt, P.; Lee, J.; Miryala, A.; Kusumaatmaja, W.; Carman, M.R.; Shtein, M.; Kieffer, J.; et al. Layer-by-layer assembled films of cellulose nanowires with antireflective properties. Langmuir 2007, 23, 7901-7906. [CrossRef] [PubMed]

75. Rivadulla, F.; Mateo Mateo, C.; Correa-Duarte, M.A. Layer-by-Layer Polymer Coating of Carbon Nanotube: Tuning of Electrical Conductivity in Random Networks. J. Am. Chem. Soc. 2010, 132, 3751-3755. [CrossRef] [PubMed]

76. Dvoracek, C.M.; Sukhonosova, G.; Benedik, M.J.; Grunlan, J.C. Antimicrobial behavior of polyelectrolytesurfactant thin film assemblies. Langmuir 2009, 25, 10322-10328. [CrossRef] [PubMed]

77. Gentile, P.; Frongia, M.E.; Cardellach, M.; Miller, C.A.; Stafford, G.P.; Leggett, G.J.; Hatton, P.V. Functionalised nanoscale coatings using layer-by-layer assembly for imparting antibacterial properties to polylactide-co-glycolide surfaces. Acta Biomater. 2015, 21, 35-43. [CrossRef] [PubMed] 
78. Li, Y.C.; Schulz, J.; Grunlan, J.C. Polyelectrolyte/Nanosilicate Thin-Film Assemblies: Influence of pH on Growth, Mechanical Behavior, and Flammability. Appl. Mater. Interfaces 2009, 1, 2338-2340. [CrossRef] [PubMed]

79. Li, Y.C.; Schulz, J.; Mannen, S.; Delhom, C.; Condon, B.; Chang, S.; Zammarano, M.; Grunlan, J.C. Flame retardant behavior of polyelectrolyte-clay thin film assemblies on cotton fabric. ACS Nano 2010, 4, 3325-3330. [CrossRef] [PubMed]

80. Laufer, G.; Carosio, F.; Martinez, R.; Camino, G.; Grunlan, J.C. Growth and fire resistance of colloidal silica-polyelectrolyte thin film assemblies. J. Colloid Interface Sci. 2011, 35669-35677. [CrossRef] [PubMed]

81. Carosio, F.; Laufer, G.; Alongi, J.; Camino, G.; Grunlan, J.C. Layer-by-layer assembly of silica-based flame retardant thin film on PET fabric. Polym. Degrad. Stab. 2011, 96, 745-754. [CrossRef]

82. Alongi, J.; Carosio, F.; Frache, A.; Malucelli, G. Layer by Layer coatings assembled through dipping, vertical or horizontal spray for cotton flame retardancy. Carbohydr. Polym. 2013, 92, 114-119. [CrossRef] [PubMed]

83. Carosio, F.; Di Blasio, A.; Cuttica, F.; Alongi, J.; Frache, A.; Malucelli, G. Flame Retardancy of Polyester Fabrics Treated by Spray-Assisted Layer-by-Layer Silica Architectures. Ind. Eng. Chem. Res. 2013, 52, 9544-9550. [CrossRef]

84. Li, Y.C.; Mannen, S.; Schulz, J.; Grunlan, J.C. Growth and fire protection behavior of POSS-based multilayer thin films. J. Mater. Chem. 2011, 21, 3060-3069. [CrossRef]

85. Carosio, F.; Alongi, J.; Malucelli, G. $\alpha$-Zirconium phosphate-based nanoarchitectures on polyester fabrics through layer-by-layer assembly. J. Mater. Chem. 2011, 21, 10370-10376. [CrossRef]

86. Li, Y.C.; Mannen, S.; Morgan, A.B.; Chang, S.C.; Yang, Y.H.; Condon, B.; Grunlan, J.C. Intumescent All-Multilayer Nanocoating Capable of Extinguishing Flame on Fabric. Adv. Mater. 2011, 23, 3926-3930. [CrossRef] [PubMed]

87. Apaydin, K.; Laachachi, A.; Ball, V.; Jimenez, M.; Bourbigot, S.; Toniazzo, V.; Ruch, D. Polyallylaminemontmorillonite as super flame retardant coating assemblies by layer-by layer deposition on polyamide. Polym. Degrad. Stab. 2013, 98, 627-634. [CrossRef]

88. Carosio, F.; Alongi, J.; Malucelli, G. Layer by Layer ammonium polyphosphate-based coatings for flame retardancy of polyester-cotton blends. Carbohydr. Polym. 2012, 88, 1460-1470. [CrossRef]

89. Alongi, J.; Carosio, F.; Malucelli, G. Influence of ammonium polyphosphate-/poly(acrylic acid)- based Layer by Layer architectures on the char formation in cotton, polyester and their blends. Polym. Degrad. Stab. 2012, 97, 1644-1653. [CrossRef]

90. Carosio, F.; Alongi, J.; Malucelli, G. Flammability and combustion properties of ammonium polyphosphate-/ poly(acrylic acid)- based Layer by Layer architectures deposited on cotton, polyester and their blends. Polym. Degrad. Stab. 2013, 98, 1626-1630. [CrossRef]

91. Zhang, T.; Yan, H.; Wang, L.; Fang, Z. Controlled formation of self-extinguishing intumescent coating on ramie fabric via layer-by-layer assembly. Ind. Eng. Chem. Res. 2013, 52, 6138-6140. [CrossRef]

92. Wang, L.; Zhang, T.; Yan, H.Q.; Peng, M.; Fang, Z.; Li, Y.; Wang, H. Flame-retardant Coating by Alternate Assembly of Poly(vinylphosphonic acid) and Polyethylenimine for Ramie Fabrics. Chin. J. Polym. Sci. 2014, 32, 305-314. [CrossRef]

93. Wang, L.; Zhang, T.; Yan, H.; Peng, M.; Fang, Z. Modification of ramie fabric with a metal-ion-doped flame-retardant coating. J. Appl. Polym. Sci. 2013, 129, 2986-2997. [CrossRef]

94. Zhang, T.; Yan, H.; Peng, M.; Wang, L.; Fang, Z. Construction of flame retardant nanocoating on ramie fabric via layer-by-layer assembly of carbon nanotube and ammonium polyphosphate. Nanoscale 2013, 5, 3013-3020. [CrossRef] [PubMed]

95. Guirao, C.; Carosio, F.; Boutevin, B.; Cottet, H.; Loubat, C. Phosphonated Oligoallylamine: Synthesis, Characterization in Water, and Development of Layer by Layer Assembly. J. Polym. Sci. Part B Polym. Phys. 2013, 51, 1244-1250. [CrossRef]

96. Carosio, F.; Negrell-Guirao, C.; Di Blasio, A.; Alongi, J.; David, G.; Camino, G. Tunable thermal and flame response of phosphonated oligoallylamines layer by layer assemblies on cotton. Carbohydr. Polym. 2015, 115, 752-759. [CrossRef] [PubMed]

97. Huang, G.; Yang, J.; Gao, J.; Wang, X. Thin films of intumescent flame retardant-polyacrylamide and exfoliated graphene oxide fabricated via layer-by-layer assembly for improving flame retardant properties of cotton fabric. Ind. Eng. Chem. Res. 2012, 51, 12355-12366. [CrossRef] 
98. Chen, S.; Li, X.; Li, Y.; Sun, J. Intumescent Flame-Retardant and Self-Healing Superhydrophobic Coatings on Cotton Fabric. ACS Nano 2015, 9, 4070-4076. [CrossRef] [PubMed]

99. Narkhede, M.; Thota, S.; Mosurkal, R.; Muller, W.S.; Kumar, J. Layer-by-layer assembly of halogen-free polymeric materials on nylon/cotton blend for flame retardant applications. Fire Mater. 2016, 40, $206-218$. [CrossRef]

100. Carosio, F.; Alongi, J. Influence of layer by layer coatings containing octapropylammonium polyhedral oligomeric silsesquioxane and ammonium polyphosphate on the thermal stability and flammability of acrylic fabrics. J. Anal. Appl. Pyrolysis 2016, 119, 114-123. [CrossRef]

101. Apaydin, K.; Laachachi, A.; Ball, V.; Jimenez, M.; Bourbigot, S.; Ruch, D. Layer-by-layer deposition of a $\mathrm{TiO}_{2}$-filled intumescent coating and its effect on the flame retardancy of polyamide and polyester fabrics. Colloids Surf. A Physicochem. Eng. Asp. 2015, 469, 1-10. [CrossRef]

102. Laufer, G.; Kirkland, C.; Morgan, A.; Grunlan, J.C. Intumescent Multilayer Nanocoating, Made with Renewable Polyelectrolytes, for Flame-Retardant Cotton. Biomacromolecules 2012, 13, 2843-2848. [CrossRef] [PubMed]

103. Zhao, L.; Yan, H.; Fang, Z.; Wang, J.; Wang, H. On the flameproof treatment of ramie fabrics using a spray-assisted layer-by-layer technique. Polym. Degrad. Stab. 2015, 121, 11-17. [CrossRef]

104. Leistner, M.; Abu-Odeh, A.A.; Rohmer, S.C.; Grunlan, J.C. Water-based chitosan/melamine polyphosphate multilayer nanocoating that extinguishes fire on polyester-cotton fabric. Carbohydr. Polym. 2015, 130, $227-232$. [CrossRef] [PubMed]

105. Fang, F.; Zhang, X.; Meng, Y.; Gu, Z.; Bao, C.; Ding, X.; Li, X.; Chen, X.; Tian, X. Intumescent flame retardant coatings on cotton fabric of chitosan and ammonium polyphosphate via layer-by-layer assembly. Surf. Coat. Technol. 2015, 262, 9-14. [CrossRef]

106. Fang, F.; Xiao, D.; Zhang, X.; Meng, Y.; Cheng, C.; Bao, C.; Ding, X.; Cao, H.; Tian, X. Construction of intumescent flame retardant and antimicrobial coating on cotton fabric via layer-by-layer assembly technology. Surf. Coat. Technol. 2015, 276, 726-734. [CrossRef]

107. Fang, F.; Chen, X.; Zhang, X.; Cheng, C.; Xiao, D.; Meng, Y.; Ding, X.; Zhang, H.; Tian, X. Environmentally friendly assembly multilayer coating for flame retardant and antimicrobial cotton fabric. Prog. Org. Coat. 2016, 90, 258-266. [CrossRef]

108. Carosio, F.; Fontaine, G.; Alongi, J.; Bourbigot, S. Starch-Based Layer by Layer Assembly: Efficient and Sustainable Approach to Cotton Fire Protection. ACS Appl. Mater. Interfaces 2015, 7, 12158-12167. [CrossRef] [PubMed]

109. Alongi, J.; Carletto, R.A.; Di Blasio, A.; Carosio, F.; Bosco, F.; Malucelli, G. DNA: A novel, green, natural flame retardant and suppressant for cotton. J. Mater. Chem. A 2013, 1, 4779-4785. [CrossRef]

110. Alongi, J.; Carletto, R.A.; Di Blasio, A.; Carosio, F.; Bosco, F.; Malucelli, G. Intrinsic intumescent-like flame retardant properties of DNA-treated cotton fabrics. Carbohydr. Polym. 2013, 96, 296-304. [CrossRef] [PubMed]

111. Carosio, F.; Di Blasio, A.; Alongi, J.; Malucelli, G. Green DNA-based flame retardant coatings assembled through Layer by Layer. Polymer 2013, 54, 5148-5153. [CrossRef]

112. Alongi, J.; Carosio, F.; Malucelli, G. Layer by layer complex architectures based on ammonium polyphosphate, chitosan and silica on polyester-cotton blends: Flammability and combustion behavior. Cellulose 2012, 19, 1041-1050. [CrossRef]

113. Huang, G.; Liang, H.; Wang, X.; Gao, J. Poly(acrylic acid)/clay thin films assembled by layer-by-layer deposition for improving the flame retardancy properties of cotton. Ind. Eng. Chem. Res. 2012, 51, 12299-12309. [CrossRef]

114. Gao, D.; Li, R.; Lv, B.; Ma, J.; Tian, F.; Zhang, J. Flammability, thermal and physical-mechanical properties of cationic polymer/montmorillonite composite on cotton fabric. Compos. Part B 2015, 77, 329-337. [CrossRef]

115. Pan, H.; Song, L.; Hu, Y.; Liew, K.M. An Eco-friendly Way to improve flame retardancy of cotton fabrics: Layer-by-Layer Assembly of semi-biobased Substance. Energy Proc. 2015, 75, 174-179. [CrossRef]

116. New, J.; Zope, I.S.; Abdul Rahman, S.N.; LiWendy Yap, X.; Dasari, A. Physiological comfort and flame retardancy of fabrics with electrostatic self-assembled coatings. Mater. Des. 2016, 89, 413-420. [CrossRef]

117. Xu, T.; Zhang, L.; Zhong, Y.; Mao, Z. Fire retardancy and durability of poly(N-benzyloxycarbonyl-3,4dihydroxyphenylalanine)-montmorillonite composite film coated polyimide fabric. J. Appl. Polym. Sci. 2014, 131. [CrossRef] 
118. Pappas, S.P. Radiation Curing. Science and Technology; Springer: New York, NY, USA, 1992.

119. Carosio, F.; Alongi, J. Few durable layers suppress cotton combustion due to the joint combination of layer by layer assembly and UV-curing. RSC Adv. 2015, 5, 71482-71490. [CrossRef]

120. Chang, S.; Slopek, R.P.; Condon, B.; Grunlan, J.C. Surface Coating for Flame-Retardant Behavior of Cotton Fabric Using a Continuous Layer-by-Layer Process. Ind. Eng. Chem. Res. 2014, 53, 3805-3812. [CrossRef]

(C) 2016 by the author; licensee MDPI, Basel, Switzerland. This article is an open access article distributed under the terms and conditions of the Creative Commons Attribution (CC-BY) license (http://creativecommons.org/licenses/by/4.0/). 